\title{
Supply Chain Management and Its Effect on Health Care Service Quality: Quantitative Evidence from Jordanian Private Hospitals
}

\author{
Raeeda Jamal Al-Saa'da ${ }^{1}$, Yara Khalid Abu Taleb ${ }^{2}$, Mais Elian Al Abdallat ${ }^{3}$, Rasmi Abd Alraheem Al-Mahasneh ${ }^{2}$, \\ Nabil Awni Nimer ${ }^{4} \&$ Ghazi A. Al-Weshah ${ }^{5}$ \\ ${ }^{1}$ Princess Iman Research \& Lab Science Center-Supply Department-Royal Medical Services, Jordan \\ ${ }^{2}$ Central Procurement branch-Royal Medical Services, Jordan \\ ${ }^{3}$ Main Medical Stores-Royal Medical Services, Jordan \\ ${ }^{4}$ Department of Biotechnology and Genetic Engineering, Philadelphia University, Jordan \\ ${ }^{5}$ Faculty of Planning \& Management, Al-Balqa Applied University, Jordan \\ Correspondence: Dr. Ghazi A. Al-Weshah, Faculty of Planning \& Management, Al-Balqa Applied University, \\ Jordan. E-mail: weshah120@yahoo.com
}

Received: February 5, 2013

Accepted: April 2, 2013

Online Published: April 27, 2013

doi:10.5430/jms.v4n2p42

URL: http://dx.doi.org/10.5430/jms.v4n2p42

\begin{abstract}
The study aims to explore and measure the effect of supply chain management's dimensions (relationship with suppliers, compatibility, specifications and standards, delivery and after-sales service) on the quality of health services' dimensions (responsiveness, trust, and security) in private hospitals in Jordan from the perspective of procurement officers. The study also aims to clarify the differences between supply chain management and quality of health services due to some demographic variables such as (gender, age, education level, and years of experience in the field of supply).

The study employs a quantitative design using a hypothesis testing approach to identify the effect of supply chain management dimensions on quality of health services. 315 questionnaires were distributed to male and female employees working in the departments of supply and procurement divided on (36) private hospital in Jordan,

The study results show that there is a significant effect of supply chain management dimensions (the relationship with suppliers, specifications and standards, and delivery, after-sales service) on the quality of health services. On the other hand, the results also indicate that there are no differences between supply chain management and the quality of health services due to gender, qualification, age, or experience.
\end{abstract}

Keywords: supply chain, service quality, quantitative analysis, hypotheses testing healthcare, Jordan

\section{Introduction}

Health organizations encounter many challenges accompanied with new requirements, namely; customer dissatisfaction, increasing cost of the health services, competition and reducing the reimbursement for services. All of these factors force the health organizations to adopt a system that can meet these requirements, dealing with the continuous changes, technology changes, increase in the health services costing, increase in competitive position and gaining customers' satisfaction (Ali et al, 2012). There is an increasing need by private hospitals administrators to adopt supply chain management; to promote the advancement of health care (Hong et al, 2012; Toba et al, 2008).

Due to cost control Supply chain management had become an important phenomenon by health care organizations in order to achieve the organization's set goals. Supply chain management (SCM) deals with different categories of flows; namely, flows of goods, flows of information and flows of funds within and among supply chain partners in order to satisfy consumer needs in the most efficient way (Chopra \& Meindl 2007). The supply chain literature has focused mainly on employing material flows to best match supply and demand. However, it is important for a competitive firm to manage and control information flows within the supply chain (Liu and Kumer 2003, Omar et al. 2010)

Supply chain management is controlling the information, materials, services and money through any activity in a way that promotes the quality of an organization's operations; it also has to do with introducing new methods and 
adjusting or enhancing old ones, adhering to the fact that efficiency is doing things right, and productivity is doing the right things (Ashcroft 2006). There are several important problems in SCM that need to be resolved for efficient operations and decisions. Most of those problems stem either from uncertainties concerned with decision making or inability to coordinate several activities and partners (Turban, McLean, \& Wetherbe, 2004). The stark reality of the global health care market is that many patients who need quality care in developed, developing and underdeveloped countries are either not receiving care or are receiving poor quality care (Murray et al. 2002).

The effects of supply chain management on health care quality, has to do with quality from an administrative point of view, medical service quality can be measured from a professionally medical perspective, or from the recipient of such services, the patient, or from an administrative perspective, which is the focus of this study. The quality of health care services rendered from an administrative perspective primarily has to do making use of available resources and the ability to attract new ones to cover the required needs of exceptional service, which provides the right service at the right time at a reasonable cost. Supply chain management (SCM) deals with the management processes of flows of goods, information and funds among supply chain partners in order to satisfy consumer needs in an efficient way (Chopra \& Meindl 2007).

Providing quality of health care service at a reasonable cost and rationalizing resources should never be at the expense of a quality performance, which requires efficiency at both the planning and executing phases, personal and professional competency and finally an internally structured philosophy to deal with external parties (Ayers. 2010). More accurately, the search for more resources requires the development of public relations with the health sector as a whole. This personal relation requirement is evident in the vague and complicated administrative organizations. The health system, in general, is vague and complicated, requiring tremendous effort for the promotion of administrative quality. This demonstrates the great importance of supply chain management and its role in ensuring the quality of medical services. Omar et al (2010) also stated that supply chain management (SCM) includes the management of product, information, and financial flow from the source of supplies to the manufacture and assembly of the product right to the delivering of the final product to consumers.

The majority of research on SCM is from the traditional manufacturing sector; however, there have been several attempts to examine its applicability in the services sector (e.g. Sengupta, Heiser and Cook 2006). Hence the study will focus on the impact of supply chain management on the quality of health services through an applied study on the sector of private hospitals in Jordan and through review of theoretical literature which dealt with the subject on the one hand, and to explore the views of those concerned in this regard, officials from the supply and procurement Jordanian private hospitals on the other.

The healthcare supply chain is composed of three major players at various stages, namely, producers, purchasers, and healthcare providers. Producers include pharmaceutical companies, medicalsurgical products companies, device manufacturers, and manufacturers of capital equipment and information systems. Purchasers include grouped purchasing organizations (GPOs), pharmaceutical wholesalers, medicalsurgical distributors, independent contracted distributors, and product representatives from manufacturers. Providers include hospitals, systems of hospitals, integrated delivery networks (IDNs), and alternate site facilities (Toba et al, 2008).

Within healthcare sectors, quality management initiatives have been raised and hospitals focus on how quality care can be delivered in order to influence outcomes with respect to hospital performance and patient satisfaction (Jiang, Friedman and Begun 2006). A developing trend in the healthcare industry is the outsourcing of supply data management to professional supply data service providers (Toba et al, 2008).

Although healthcare industries have faced serious competitive challenges through their network alliance, a sustainable competitive advantage of healthcare supply chain has not been well examined (Hong et al, 2012). There is an increasing evidence that emphasis quality management initiatives and focus on how healthcare quality can be delivered in order to influence outcomes with respect to hospital performance and patient satisfaction (Jiang et al. 2006; Toba et al, 2008).

The paper, firstly presents a review of the literature pertaining to the concept of supply chain dimensions and quality measurement in health care industry scope. Thereafter, the paper explains the methodology employed in this research. The study results are then analyzed and interpreted in the light of theoretical evidence reported in extant literature. Finally, a number of conclusions drawn from this investigation are discussed, along with limitations of the study and avenues of future research. 


\section{The Study Aim and Objectives}

The current study aims at clarifying the impact of supply chain management on the quality of health services in hospitals in the Jordanian private hospitals sector from the supply chain officers' perspectives. More specifically, the objectives of the study are to:

Identify the current status of supply chain in Jordanian private hospitals sector.

$>$ Identify the current status of supply chain in Jordanian private hospitals sector.

$>$ Measure the effect of supply chain management dimensions (the relationship with suppliers, specifications, standards, delivery, and after-sales service) on the quality of health services dimensions (responsiveness, trust, and safety).

$>$ Measure difference for the management of the supply chain due to personal and functional characteristics (gender, age, educational level, experience).

\subsection{Hypotheses of the Study}

The current study includes two main hypotheses as follows:

2.1.1 The First Hypothesis: There is no significantly statistical effect for supply chain management dimensions (the relationship with suppliers, specifications, standards, delivery, and after-sales service) on the quality of health services dimensions (responsiveness, trust, and safety).

2.1.2 The Second Hypothesis: There is no significantly statistical difference for the management of the supply chain due to personal and functional characteristics (gender, age, educational level, experience).

\subsection{The Study Framework}

Figure 1 shows framework of the study which includes independent and dependent variables, as well as some demographic variables which are related to the study.

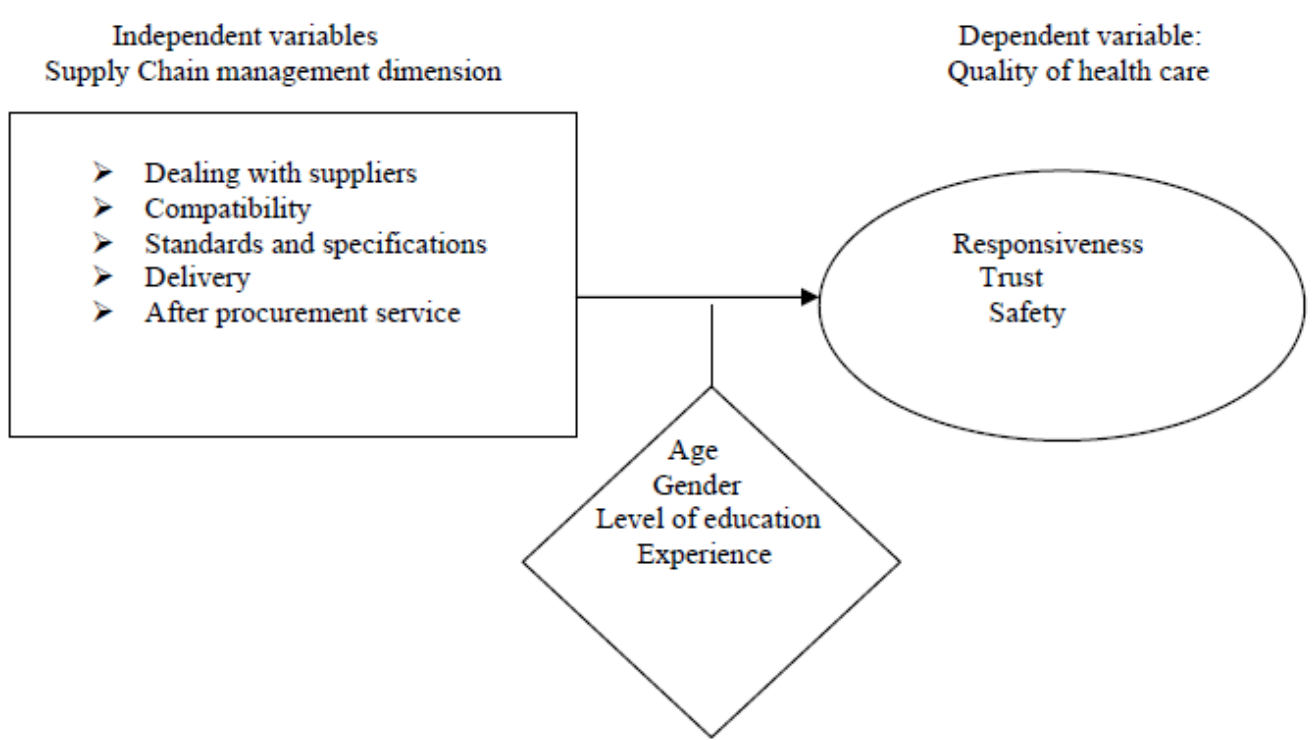

Figure 1. The study conceptual framework

Source: (Ross, 2008; Shaikh \& Rabbani, 2005)

The study framework defines the relationships between dimensions of healthcare supply chain management (relationship with suppliers, compatibility, specifications and standards, delivery and after-sales service) on the quality of health services' dimensions (responsiveness, trust, and security) in private hospitals in Jordan from the perspective of procurement officers.

2.2.1 Independent Variable (Supply Chain Management): the administrative unit that deals with suppliers (medical companies) directly and determine the demand and specifications and conditions of purchase and receipt of all from the Department of Supply and Procurement Section in private hospitals (Demeter \& Gelei, 2004).

The dimensions of a quality health service are represented through: 
> Relationship with suppliers: the relationship of supply officers in hospitals with the companies that supply products to the hospital.

$>$ Specifications and standards: specifications set by the supply officers as conditions for the supply in the tender.

Delivery: indicates to delivery dates between the supply officer at the hospital and the company that supply medical equipment and supplies. Delivery represents financial or contractual arrangements amongst physicians, hospitals, and patients (Dobrzykowski et al, 2012).

$>$ After procurement service: follow-up maintenance and service and supply parts and needs by suppliers to the hospital after the sale.

> Compatibility: Compatibility in strategic objectives and cultural values of business partners facilitates supply chain capabilities (Rajesh and Matanda, 2012). Compatibility is the appropriateness of medical equipment and supplies to the specifications and standards that have been agreed upon between the supply administrator in the hospital and the company that supplied such equipment and supplies.

2.2.2 Dependent Variable (Quality of Health Services): the delivery of health care services and it's continuous improvements to meet the needs of patients, through work completion by highly skilled staff members dedicated to high quality service (shaikh, 2005)

\section{The dimensions of a quality health service are represented through:}

$>$ Responsiveness: suppliers speed and accuracy in response to client requests (hospital). Responsiveness has high validity and reliability in measuring the quality of services in health care sector. (Kazemzadeh et al., 2011).

Drust: The degree of reliability enjoyed by the supplier from the viewpoint of supply officers at the hospital. Trust is conveyed through faith, reliance, belief, or confidence in the supply partner (Spekman et al, 1998)

$>$ Safety: service provided to be free from uncertainty, risk and doubt to a certain degree. By increasing the complexity of health care, the demand for improving patient safety and monitoring the quality of services has become a critical issue (Manias, 2010)

The service quality includes two dimensions; the first dimension deals with procedures and specific systems which are established to provide the service, while the second is a personal and concerned with the interaction among workers and their attitudes and behaviors with customers (Abu-Kharmeh, 2012).

\section{Literature Review}

Hong et al, (2012) proposed a research model which defines the relationships between drivers of healthcare supply chain management, healthcare supply chain policies and strategy, healthcare supply chain practices, and healthcare supply chain outcomes. Their study discussed drivers of healthcare supply chain management in Korean context in terms of their strategic focus on healthcare supply chain processes and healthcare cost performance.

Dobrzykowski et al. (2010) described how the healthcare delivery supply chain is decentralized, in other words, lacking in traditional financial and contractual coordination mechanisms among supply chain members. It suggests that partner relationship as a coordinating mechanism capable of influencing a hospital's integrative information, resource strategy, and partnership culture leading to integration of the supply chain during care delivery. Bozarth et al., (2009) presented four models of the supply chain which is used in (209) factories over seven European countries, the study used four different models of the supply chain created by the researchers themselves. The results showed that the greater the complexity of the supply chain model in the plant reflected negatively on performance, while factories that have used a simple supply chain model shown more success in the level of performance.

Fredenall et al. (2009) investigated an internal supply chain for perioperative surgical services and attempted to explore reasons for operational failures and productivity loss. They concluded that there are a number of factors including a lack of process standardization, no effective mechanisms for dealing with bottlenecks or quality problems and, finally, that the use of routines improved relational coordination but that even consensus between departments did not sufficiently improve work flows Sinha and Kohnke (2009) presented a macro-perspective of the healthcare supply chain which shows the development of healthcare is linked to the delivery of care through the interdependence of industries that span new service and product development to delivery organizations. This chain includes such development industries as medical devices, pharmaceutical, biotechnology firms which are connected both directly and through the health care finance industry to the health care delivery sector. 
Al-Taher (2008) investigated the ability of the Ministry of Health to provide health services to citizens in Sudan based on its financial resources. Using questionnaire, the study measures the impact of poor performance of health services provided by the Ministry of Health in the state of Khartoum. The study results showed the adequacy of financial resources available to the Ministry of Health in the state of Khartoum to provide health services, the results also showed that weaknesses in the adequacy of financial resources reflected in some of the areas, including: lack of manpower in the delivery of health services, and the weakness of aids and services necessary assistance to provide health services, and weak financial incentives to health care employees.

Shah et al. (2008) used a field approach of study to examine how a particular health care supply chain was able to increase performance by decreasing service time and increasing service quality in a decentralized network of health care providers. They concluded that the use of lean principles can guide process improvement efforts and the emphasis relational based coordination allowed the organizations to dramatically improve the supply chain performance.

Hendricks \& Singhal (2005) identified linking factors between weaknesses in the supply chain and operational performance of industrial American companies in Florida. The study results showed that the return on sales and return on assets occupied the first ranks in the impact on operational performance; the study indicated that companies -suffering from different problems in the supply chain- have suffered from low growth, high operational costs, and low profits. Boyer and Hult (2005) stated that there are important operations, marketing, and information technology components to a service supply chain. These components are critical to whether or not the customer will intent to do more business with the firm. The study identified the keys to customer intent in order to repurchase as product quality, service quality, and e-business quality

More specifically in Jordan, Ali et al. (2012) explored the extent of applying TQM in hospital performance in the Jordanian hospitals. The study includes two health sectors, namely: the public (King Abdullah University Hospital, Irbid) and the private (Jordan Hospital and Medical Center, Amman). The findings of the study showed that the eight principles of Total Quality Management are highly correlated with hospital performance likewise overall TQM has significant positive relationship with hospital performance in the Jordanian context. Abu-Kharmeh (2012) evaluated the quality of health care services provided in Jordan. The quality was measured by five dimensions, namely, tangibility, reliability, responsiveness, assurance, and empathy. The results indicated that the level of health services quality provided to patients in Jordanian hospitals was moderate; the service quality dimensions were also moderate except responsiveness and assurance variables that were high. The responsiveness came at the first rank while the reliability ranked lastly.

\section{The Study Methodology}

This study adopted quantitative design using a hypothesis testing approach to identify the effect of supply chain management on quality of health services. Questionnaire was developed as data collection instrument. The sample study consisted of the supply and procurement officers in (36) private hospitals operating in the Jordanian capital of Amman, totally (315) questionnaires were distributed to male and female employees working in the departments of supply and procurement, 307 questionnaires were returned and 6 questionnaires were excluded from the analysis due to incomplete answers,

Thus, (301) questionnaires were used in analysis and hypothesis testing. The study tool has been prepared constructed into two parts; the first part is to measure the supply chain and divided on four dimensions: the relationship with suppliers, specifications and standards, delivery and after service supply, consisted of (15) questions. While the second part of the questionnaire, which measures the quality of health services divided into four dimensions: the relevance, responsiveness, trust and security, and is consisted of (25) questions.

To ensure the questionnaire validity, the questionnaire was "pilot-examined" by interviewing 4 managers and experts in the supply chain departments who agreed to fill in the questionnaire and also to comment on the scales employed. Then, their suggestions were collected and considered to improve validity of questionnaire. Moreover, the questionnaire was pre-tested by sending three questionnaires to different supply chain managers to get their comments and feedback. For the purpose of ensuring the reliability of the questionnaire, Cronbach's alpha was used as a measure of internal consistency reliability. A widely cited minimum threshold for the Crobanch Alpha is 0.70 (Malhotra, 2004). However, the calculated Cronbach's Alpha for the questionnaire as whole was 0.86 percent as shown in appendix $1.86 \%$ indicates to high internal consistency among the questions in the questionnaire instrument. 
Table 1. Characteristics of the study sample

\begin{tabular}{|c|c|c|c|c|}
\hline Variable & Categories & Frequency & Percentage & Total \\
\hline \multirow{2}{*}{ Gender } & Male & 262 & 87.0 & \multirow{2}{*}{301} \\
\hline & Female & 39 & 13.0 & \\
\hline \multirow{3}{*}{ Age } & Less than 30 & 11 & 3.7 & \multirow{4}{*}{301} \\
\hline & $31-40$ & 37 & 12.3 & \\
\hline & $41-50$ & 201 & 66.8 & \\
\hline \multirow{5}{*}{ Educational level } & More than 51 & 52 & 17.3 & \\
\hline & Diploma & 32 & 10.6 & \multirow{4}{*}{301} \\
\hline & BA & 155 & 51.5 & \\
\hline & MA & 98 & 32.6 & \\
\hline & $\mathrm{PhD}$ & 16 & 5.3 & \\
\hline \multirow{4}{*}{$\begin{array}{l}\text { Experience } \\
\text { years }\end{array}$} & Less than 5 & 17 & 5.6 & \multirow{4}{*}{301} \\
\hline & $5-10$ & 155 & 51.5 & \\
\hline & $11-15$ & 92 & 30.6 & \\
\hline & More than 15 & 37 & 12.3 & \\
\hline
\end{tabular}

As shown in Table 1, most of the questionnaire respondents are males (87\%), also the majority of the study respondents were aged between 41-50 years. Bachelor's degree holders are the largest percentage among members of the study sample. According to experience years, the majority of the questionnaire respondents have experience years between 5-10 years.

\section{Hypotheses Testing}

The first hypothesis: there is no significant effect at the level of significance $(\alpha \leq 0.05)$ for the dimensions of the supply chain management (the relationship with suppliers, specifications, standards, delivery, and after-sales service) on the quality of health services.

To test the hypothesis, simple regression analysis has been used to identify the impact of supply chain management dimensions (the relationship with suppliers, specifications, standards, delivery, and after-sales service) on the quality of health services.

Table 2 shows results of the simple regression analysis for the impact of supply chain management dimensions the relationship with suppliers, specifications, standards, delivery, and after-sales service) on the quality of health services.

Table 2. The simple regression analysis

\begin{tabular}{ccccc}
\hline & \multicolumn{4}{c}{ Quality of healthcare services } \\
\cline { 2 - 5 } Variables & $\begin{array}{c}\text { Beta } \\
\text { value }\end{array}$ & $\begin{array}{c}\text { coefficients of } \\
\text { correlation } \\
(\mathrm{R})\end{array}$ & $\begin{array}{c}\text { coefficients of } \\
\text { determination } \\
\left(\mathrm{R}^{2)}\right.\end{array}$ & $\begin{array}{c}\text { Significant } \\
\text { level }\end{array}$ \\
\hline Supply chain management & 25.04 & 0.50 & 0.25 & 0.00 \\
Relationship with suppliers & 57.72 & 0.40 & 0.16 & 0.00 \\
Specifications and standards & 54.87 & 0.39 & 0.16 & 0.00 \\
Delivery & 41.57 & 0.35 & 0.12 & 0.00 \\
After sale service & 68.47 & 0.43 & 0.19 & 0.00 \\
\hline
\end{tabular}

Table 2 shows that the correlation coefficient of supply chain management dimensions (the relationship with suppliers, specifications, standards, delivery, and after-sales service) with the quality of healthcare services is $(0.50)$ and the value of (beta) was 25.04 with a level of significance 0.00 , therefore, the hypothesis zero is rejected and the alternative hypothesis is accepted, consequently, there is a significant impact of supply chain management dimensions (the relationship with suppliers, specifications, standards, delivery, and after-sales service) on the quality of healthcare services. 
$\mathrm{R}^{2}$ ratio is the proportion of variation (change) in quality of healthcare services that can be explained by supply chain management dimensions (the relationship with suppliers, specifications, standards, delivery, and after-sales service). Therefore, this ratio $(0.25)$ indicates to the relative contribution supply chain management dimensions in interpreting the quality of healthcare services. Thus, the alternative hypothesis is confirmed there is a significant impact of supply chain management dimensions (the relationship with suppliers, specifications, standards, delivery, and after-sales service) on the quality of healthcare services.

$>$ The second main hypothesis: There is no statistically significant differences at the level of significance $(\alpha \leq 0.05)$ for supply chain management on the quality of health services due to personal and functional variables (gender, age, educational level, number of years of experience in the field of supply).

To test the hypothesis, analysis of variance has been used to statistical differences between supply chain management dimensions (the relationship with suppliers, specifications, standards, delivery, and after-sales service) and the quality of health services.

Table 3 shows the results of analysis of variance for differences in supply chain management on the quality of health services due to Gender

Table 3. Differences between supply chain management and the quality of health services due to gender

\begin{tabular}{|c|c|c|c|c|c|}
\hline $\begin{array}{c}\text { Sources of } \\
\text { Variation }\end{array}$ & Squares average & $\begin{array}{l}\begin{array}{l}\text { Degree } \\
\text { freedom }\end{array} \\
\end{array}$ & $\begin{array}{l}\text { Sum of } \\
\text { squares }\end{array}$ & $\mathrm{T}$-value & $\begin{array}{l}\text { Significant } \\
\text { level }\end{array}$ \\
\hline Between samples & 260.22 & 1 & 260.22 & 1.69 & 0.19 \\
\hline $\begin{array}{c}\text { Inside the samples } \\
\text { Total }\end{array}$ & 154.08 & $\begin{array}{l}299 \\
300\end{array}$ & $\begin{array}{l}46070.78 \\
46331.00\end{array}$ & & \\
\hline
\end{tabular}

As shown in the Table 3, the statistical value of (T) is 1.69 which is not a function at a level of significance $(\alpha \leq$ 0.05 ). Therefore, there is no significant difference between the supply chain management and the quality of health services attributed to gender.

Table 4 shows the results of the analysis of variance for differences in supply chain management on the quality of health services due level of education.

Table 4. Differences in supply chain management on the quality of health services due level of education

\begin{tabular}{|c|c|c|c|c|c|}
\hline $\begin{array}{l}\text { Sources of } \\
\text { Variation }\end{array}$ & Squares average & $\begin{array}{ll}\begin{array}{l}\text { Degree } \\
\text { freedom }\end{array} & \text { of } \\
\end{array}$ & $\begin{array}{l}\text { Sum of } \\
\text { squares }\end{array}$ & $\mathrm{T}$-value & $\begin{array}{l}\text { Significant } \\
\text { level }\end{array}$ \\
\hline Between samples & 314.15 & 3 & 942.45 & 2.06 & 0.11 \\
\hline Inside the samples & 152.82 & 297 & 45388.55 & & \\
\hline Totals & & 300 & 46331.00 & & \\
\hline
\end{tabular}

As shown in the Table 4 the statistical value of (T) is 2.06 which is not a function at a level $(\alpha \leq 0.05)$. Therefore, there is no significant difference between the supply chain management and the quality of health services due educational level.

Table 5 shows the results of the analysis of variance for differences between supply chain management and the quality of health services attributed to Age.

Table 5. Differences between supply chain management and the quality of health services attributed to age

\begin{tabular}{|c|c|c|c|c|c|}
\hline $\begin{array}{c}\text { Sources of } \\
\text { Variation }\end{array}$ & Squares average & $\begin{array}{l}\begin{array}{l}\text { Degree } \\
\text { freedom }\end{array} \\
\end{array}$ & $\begin{array}{l}\text { Sum of } \\
\text { squares }\end{array}$ & $\mathrm{T}$-value & $\begin{array}{l}\text { Significant } \\
\text { level }\end{array}$ \\
\hline Between samples & 199.23 & 3 & 597.70 & 1.29 & 0.28 \\
\hline Inside the samples & 153.98 & 297 & 45733.29 & & \\
\hline Total & & 300 & 46331.00 & & \\
\hline
\end{tabular}

As shown in the Table 5 the statistical value of (T) is 1.29 which is not a function at a level $(\alpha \leq 0.05)$. Therefore, there is no significant difference between the supply chain management and the quality of health services due age.

Table 6 shows the results of analysis of variance for differences between supply chain management and the quality of health services due to experience years. 
Table 6. Differences between supply chain management and the quality of health services due to experience years

\begin{tabular}{cccccc}
$\begin{array}{c}\text { Sources of } \\
\text { Variation }\end{array}$ & Squares average & $\begin{array}{l}\text { Degree } \\
\text { freedom }\end{array}$ & $\begin{array}{c}\text { of } \\
\text { squares }\end{array}$ & $\begin{array}{c}\text { Sum of } \\
\text { T -value }\end{array}$ & $\begin{array}{l}\text { Significant } \\
\text { level }\end{array}$ \\
\hline Between samples & 204.93 & 3 & 614.80 & 1.33 & 0.26 \\
Inside the samples & 153.93 & 297 & 45716.20 & & \\
Total & & 300 & 46331.00 & \\
\hline
\end{tabular}

As shown in the Table 6 the statistical value of (T) is 1.33 which is not a function at a level $(\alpha \leq 0.05)$. Therefore, there is no significant difference between the supply chain management and the quality of health services due to experience years.

\section{Conclusions and Implications}

The aim of this study was to measure the effect of supply chain management on the quality of healthcare services in Jordanian private hospitals sector from the supply chain officers' perspectives. The results showed that there is a medium relationship between the supply chain management dimensions (the relationship with suppliers, specifications, standards, delivery, and after-sales service) and the quality of healthcare services. The relative contribution supply chain management dimensions in interpreting the quality of healthcare services was $(0.25)$. Thus, the alternative hypothesis is confirmed there is a significant impact of supply chain management dimensions (the relationship with suppliers, specifications, standards, delivery, and after-sales service) on the quality of healthcare services. Consequently, there is a significant impact of supply chain management dimensions (the relationship with suppliers, specifications, standards, delivery, and after-sales service) on the quality of healthcare services.

The results also showed that there are no significant differences between supply chain management dimensions and the quality of healthcare services due to some demographic factors such as gender, educational qualification, age, and experience. These results are consistent with recent study in Jordan, The result is consistent with the Jordanian healthcare environment, as around 33\% of the health care provided in Jordan is obtained in the private sector (JMH, 2010), which provides primary, secondary, and tertiary services through a network of private clinics and hospitals, mostly concentrated in the capital and other urban centers. This includes 58 hospitals with a total of 3642 hospital beds (33\%).

The current study-based on literature- developed a new model which depicts the effect of supply chain management dimensions on service quality measurement in health care sector. The proposed model can be extended to different services industries. The study revealed different implications for Jordanian healthcare services which are supported by other studies conducted in Jordan such as (Abu kharmeh, 2012). It is necessary for hospital managers to recognize patients' needs and expectations. Hospital management can take into account the levels of their ages and their future needs. Hospitals also have to pay attention to select and recruit staffs that are scientifically and practically qualified, especially in the field of health administration.

The study also enhanced the importance of supply chain management in service sectors and its effect on service quality. Although a number of studies have attempted to apply principles and frameworks from the manufacturing sector to the service sector such as (Vandaele and Gemmel, 2007), a significant number of other research has emphasized the uniqueness of the service supply chain and called for more studies which account for these factors.

In order to improve the quality of care, health specialists should be trained in the field of how to offer care in an effective and efficient manner. But these specialists always face with difficulties in evaluating their experiences and this is mostly because of not being aware about the methods of quality measurement. Kazemzadeh et al (2011) concluded that health care managers' knowledge about service quality factors is a very important element in continuous quality improvement.

\subsection{Recommendations for Practice}

Based on the study results, some recommendations can be proposed by the study; Firstly, hospitals need to focus on supply chain activities in order to improve quality of healthcare services. Secondly, supply chain officers' need to contribute significantly to increase the quality of health services provided to different beneficiaries. Thirdly, hospital management should focus on recruiting highly skilled and specialized personnel in the supply chain departments and subject them to intensive training courses in international quality standards; therefore, they can deal with suppliers in accordance with specific guidelines. 
Fourthly, there are growing needs to arrange training courses for staff members who work in hospitals on the supply chain management and the quality healthcare service. Finally, Adopting hospital for SCM mandates a change in thinking ways as well as practices. It means that SCM needs to define its role, tasks, and begin to employ value-added activities across the value chain aspects. It can no longer silo itself focusing on downstream, low-value-added, opportunistic efforts to improve quality of health care services.

\subsection{Recommendations for Further Research}

The current study investigated the effect of supply chain dimensions on service quality in Jordanian private hospitals. More specifically, it is limited to private hospitals which are operating in Jordan. Therefore, the study will not include governmental or military hospitals in Jordan. Moreover, the current study did not consider the qualitative approach of analysis.

In light of the study limitations, further prospective studies related to the health sector can be conducted especially comparative studies between public, private and military health service sectors. Moreover, the proposed model in the study can be extended to include different service sectors. Methodologically, the future studies can consider the qualitative approach to understand the role of supply chain in quality of services in health service sector.

\section{References}

Abu-kharmeh, S. (2012). Evaluating the quality of healthcare services in the Hashemite of kingdom of Jordan. International Journal of Business and Management, 7(4), 195-205

Ali, K., Alolayyan, M., \& Idris, F. (2012). The impact of total quality management (TQM) on hospital performance in the Jordanian hospitals: an empirical evidence (medical leader's perspectives). Global conference on operations and supply chain management (GCOM2012) proceedings, 12-13 March 2012. Bandung, Indonesia.

Al-Taher, A. (2008). The Impact of Financial Resources on Health Services Performance: Ministry of Health, Khartoum State. Unpublished master's thesis, Institute of Development studies and Research Institute, University of Khartoum- Sudan.

Ashcroft, J. (2006). Eight Dimensions of Supply Chain Synchronization, National Business to Business Center, International Digital Laboratory. University of Warwick, UK.

Ayers, J. (2010). Supply Chain Project Management: A Structured Collaborative and Measurable Approach (2 ${ }^{\text {nd }}$ ed.). Florida: Auerbach Publications, USA.

Boyer, K., \& Hult, G. (2005). Extending the Supply Chain: Integrating Operations and Marketing in the Online Grocery Industry. Journal of Operations Management, 23(6), 642-661. http://dx.doi.org/10.1016/j.jom.2005.01.003

Bozarth, C., Warsing, D., Flynn, B., \& Flynn, K. (2009). The impact of supply chain complexity on manufacturing plant performance. Journal of Operations Management, 27(1), 78-93. http://dx.doi.org/10.1016/j.jom.2008.07.003

Chopra, S., \& Meindl, P. (2007). Supply Chain Management: Strategy, Planning and Operation. Pearson Education, New Jersey.

Dobrzykowski, D., Nathen, T., \& Vonderembse, M. (2012). Integrating the decentralized healthcare delivery supply chain. POMS 21st Annual Conference. Vancouver, Canada.

Fredendall, L. D., Craig, J., Fowler, P., \& Damali, U. (2009). Barriers to swift, even flow in the internal supply chain of perioperative surgical services department: A case study. Decision Sciences, 40(2), 327-349. http://dx.doi.org/10.1111/j.1540-5915.2009.00232.x

Hendricks, K., \& Singhal, V. (2005). Association between Supply Chain Glitches and Operating Performance. Journal of Management Science, 51(5), 695-711. http://dx.doi.org/10.1287/mnsc.1040.0353

Hong, P., Kim, S., \& Dobrzykowski, D. (2012). Healthcare supply chain for competitive advantage: the case for Korea. 5TH Annual Symposium and Workshop in Global Supply Chains, March 8-10, 2012, Tokyo, Japan.

Jiang, H. J., Friedman, B., \& Begun, J. (2006). Factors Associated with High-Quality/Low-Cost Hospital Performance. Journal of Health Care Finance, 32(3), 39-52.

Jordanian Ministry of Health. (2010). Annual Statistical Report. 
Kazemzadeh, R., Jahantigh, F., Rafie, S., \& Maleki, N. (2011). Designing a conceptual model for quality measurement in supply chain of health care services. 3rd International Conference on Advanced Management Science, IACSIT Press, Singapore.

Liu, E., \& Kumer, A. (2003). Leveraging information sharing to increase supply chain configurability. Twenty fourth international conference on information system.

Manias, E. (2010). Medication communication: a concept analysis. Journal of Advanced Nursing, 66(4), 933-943. http://dx.doi.org/10.1111/j.1365-2648.2009.05225.x

Omar, R. Ramayah, T., Lo, M., Sang, T., \& Siron, R. (2010). Information sharing, information quality and usage of information technology (IT) tools in Malaysian organizations. African Journal of Business Management, 4(12), 486-499.

Rajesh, R., \& Matanda, M. (2012). Effects of inter-organizational compatibility on supply chain capabilities: Exploring the mediating role of inter-organizational information systems (IOIS) integration, Industrial

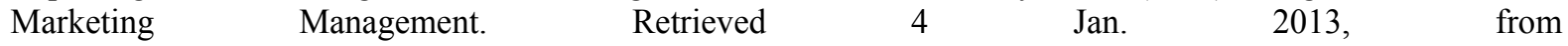
http://www.sciencedirect.com/science/article/pii/S0019850112001629

Ross, D. (2008). The Intimate Supply Chain: Leveraging the Supply Chain to Manage the Customer Experience. New York: Taylor \& Francis Group, USA. http://dx.doi.org/10.1201/9781420064988

Sengupta, K., Heiser, D., \& Cook, L. (2006). Manufacturing and Service Supply Chain Performance: A Comparative Analysis. Journal of Supply Chain Management: A Global Review of Purchasing \& Supply, 42(4), 5-16.

Shah, R., Goldstein, S., Unger, B., \& Henry, T. (2008). Explaining Anomalous High Performance in a Health Care Supply Chain. Decision Science, 39(4), 759-788. http://dx.doi.org/10.1111/j.1540-5915.2008.00211.x

Shaikh, B. (2005). Quality of Health Care: An absolute for Patient Satisfaction. Journal of View Point, 55(11), 495-525.

Shaikh, B., \& Rabbani, A. (2005). Health Management Information System: A tool to gauge patient satisfaction \& quality of care. Eastern Mediterranean Health, 11(1), 2-23.

Sinha, K., \& Kohnke, E. (2009). Health Care Supply Chain Design: Toward Linking the Development and Delivery of Care Globally. Decision Sciences, 40(2), 197-212. http://dx.doi.org/10.1111/j.1540-5915.2009.00229.x

Spekman, R., Jr, J., \& Myhr, N. (1998). An empirical investigation into supply chain management: A perspective on partnerships. International journal of physical distribution and logistics, 28(8), 630-650. http://dx.doi.org/10.1108/09600039810247542

Toba, S., Tomasini, M., \& Yang, H. (2008). Supply chain management in hospitals: a case study. California Journal of Operations Management, 6(1), 49-55.

Turban, E., McLean, E., \& Wetherbe, J. (2004). Information technology for management (4th ed.). NewYork: John Wiley \& Sons.

Vandaele, D., \& Gemmel, P. (2007). Purchased Business Services Influence Downstream Supply Chain Members. International Journal of Service Industry Management, 18(3), 307-21. http://dx.doi.org/10.1108/09564230710751505

Appendix 1. Internal consistency coefficients for the whole questionnaire and for each dimension of the study

\begin{tabular}{llc}
\hline \multicolumn{1}{c}{ Dimensions of the variables } & \multicolumn{1}{|c}{ Paragraph Sequence } & $\begin{array}{c}\text { Reliability } \\
\text { Coefficient } \\
\text { Cronbach's } \\
\text { Alpha }\end{array}$ \\
\hline Relationship with suppliers & $1,2,3,4,5$ & 85.1 \\
Standards and specifications & $6,7,8,9$ & 91.0 \\
Delivery & $10,11,12$ & 92.1 \\
After Procurement Service & $13,14,15$ & 90.0 \\
Compatibility & $16,17,18,19,20,21,22,23$ & 85.1 \\
Responsiveness & $24,25,26,27$ & 92.0 \\
Trust & $28,29,30,31,32,33,34$ & 92.0 \\
Security & $35,36,37,38,29,40$ & 91.1 \\
Total & & 0.86 \\
\hline
\end{tabular}

